\title{
AN INSCRIBED MONUMENT FROM THE OCOSINGO VALLEY
}

Gary W. PahL UCLA Latin American Center

Among the monument types typical of Tonina and the Ocosingo Valley (figure 1) in the western periphery of the Classic Period Maya area are rectangular cut stone slabs with circular holes carved through the center. Franz Blom and Oliver La Farge (1927: 275) who made survey visits to the Ocosingo Valley published these stone monuments as "bases for stelae." This nomenclature is somewhat misleading because the stelalike monuments at Toniná are actually statuary carved in full and 3/4 round. Inscriptions on these statues are carved on the backs of the statues, on the loin clothes draped down the front of the statues, and sometimes on arms and legs as tatoos. The perforated "bases" served as sockets for the tenoned

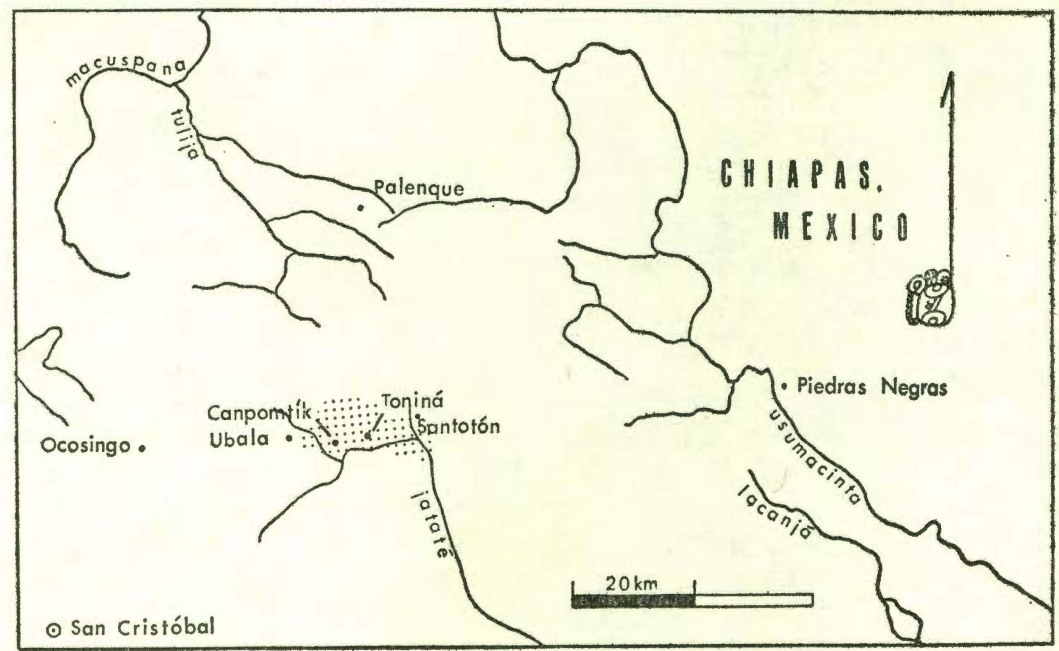

Figure 1. Map of the Toniná area. The Ocosingo Valley is demarcated by the stippled area. 
stone tabs extending downward from the bases of the statuary. These were also inscribed with hieroglyphic texts on their sides.

One such perforated slab (figures 2 and 3) with inscriptions was spirited out of an unknown site in the Ocosingo Valley by a private collector in the Los Angeles area. The collector contends that the monument was looted from Toniná proper but textual information on the monument suggest otherwise. Normally, it would not please me to see plundered monuments published, but the hieroglyphic text of the monument offers information which may prove to be important to the understanding of the Maya civilization's structure and operation in the Ocosingo Valley.

The text is relatively straight forward. The text begins (figure 3 and table 1) with a clear Calendar Round date of 4 Ahau $18 \mathrm{Xul}$ (AI-CI) which yields a Long Count date of 0.18.15.15.0 or 10.1.8.10.0.

TABLE 1: Thompson numbers from the hieroglyphic text on the sides of the Ocosingo Valley monument.

Al IV Ahau

B1 G3 of the G Series or Lords of the Night

Cl XVIII Xul

D1 819 day calendar symbol

E1 61: 568.756 v ( 521 or 544 in human sacrifice? mouth)

F1 281:23.528:116 reversed function unclear

G1 III Katuns

H1 Glyph X of the Lunar Series?

I1 36.168: no number in Thomp- (emblem glyph) son Catalog. 116:131

J1 24.117:1030v

K1 16.67lv:?:181

L1 59.125:19 as mainsign

M1 117.168:671:116

N1 28:528.513

function unclear name?

name?

(possible emblem glyph) function unclear

Material: yelow sandstone (the same material type found at Toniná)

Length: $\quad 56 \mathrm{~cm}$.

Width: $\quad 43 \mathrm{~cm}$.

Thickness: $\quad 16 \mathrm{~cm}$.

Perforation: $21.5 \mathrm{~cm}$. (diameter)

Glyph Height: $10 \mathrm{~cm}$.

Incision:

$.75 \mathrm{~cm}$. (depth) 
The earlier date is confirmed by the Lunar Series Glyph G3 at B1. Thompson (personal communication) noted that the free "use of Glyphg to date Calendar Round dates is typical of Chiapas." Thompson originally demonstrated the Calendar Round confirmation technique wit hthe G Series in 1942.

The glyph at $\mathrm{Dl}$ is of interest because it almost always occurs in monumental texts with the 819 day calendar notations. On both the monumental texts and in the codices the 819 day count is associated with world directions. But here there seems to be no directional association unles F1, T281: 23. 528:116:24, or Yellow Year is used as a directional indicator of some sort. The Kan-cross, T281, is frequently associated with the T23 affix, al, which is a common terminal affix for "color names-chacal, zacal, kanal when they are used adjectivally" (Thompson 1962: 67).

The glyph compound at E1, T61: $568.756 \mathrm{v}$ (521 or 544 in mouth) is not clear in this context as T568 is usually accepted as connotating human sacrifice, especially in the company of a bat glyph. Perhaps the compound indicates that a sacrifice is associated with the date of the monument.

An unusual expression of the Katun sign follows the Kanal haabil (F1) expression at Gl. The numerical coefficient, three, and the winged ka element, T28, are normal, but a female head (T1000v) and a postfix not included in the Thompson catalog replace the expected Tun mainsign. The compound at $\mathrm{Hl}$ is apparently a variant of Glyph $\mathrm{X}$ of the Lunar Series although its function here is not clear.

The compound at Il is an emblem glyph which has not been certainly identified to date. The mainsign of the emblem glyph is similar to T644, the seating glyph, but the diagonal band between the circle at the top and the bottom of the mainsign set it apart from the Thompson Catalog holdings.

From the form of the monument and the reported provenience of the monument, it might be suggested that the emblem glyph is a variant of the known Toniná emblem glyph (Baudez and Becquelin 1975) which employs an Ich mainsign. An emblem glyph which closely resembles the Toniná emblem glyph and the one on this monument is illustrated by Michael Coe (1973: 33) on the sides of a stone box containing a jade head (E1). Unfortunately, the provenience for the box and head are unknown as they are also contraband. Coe suggests that the box and head are from the Usumacinta region but are rendered in the style of Palenque workmanship. Without too much difficulty the emblem glyph on the 


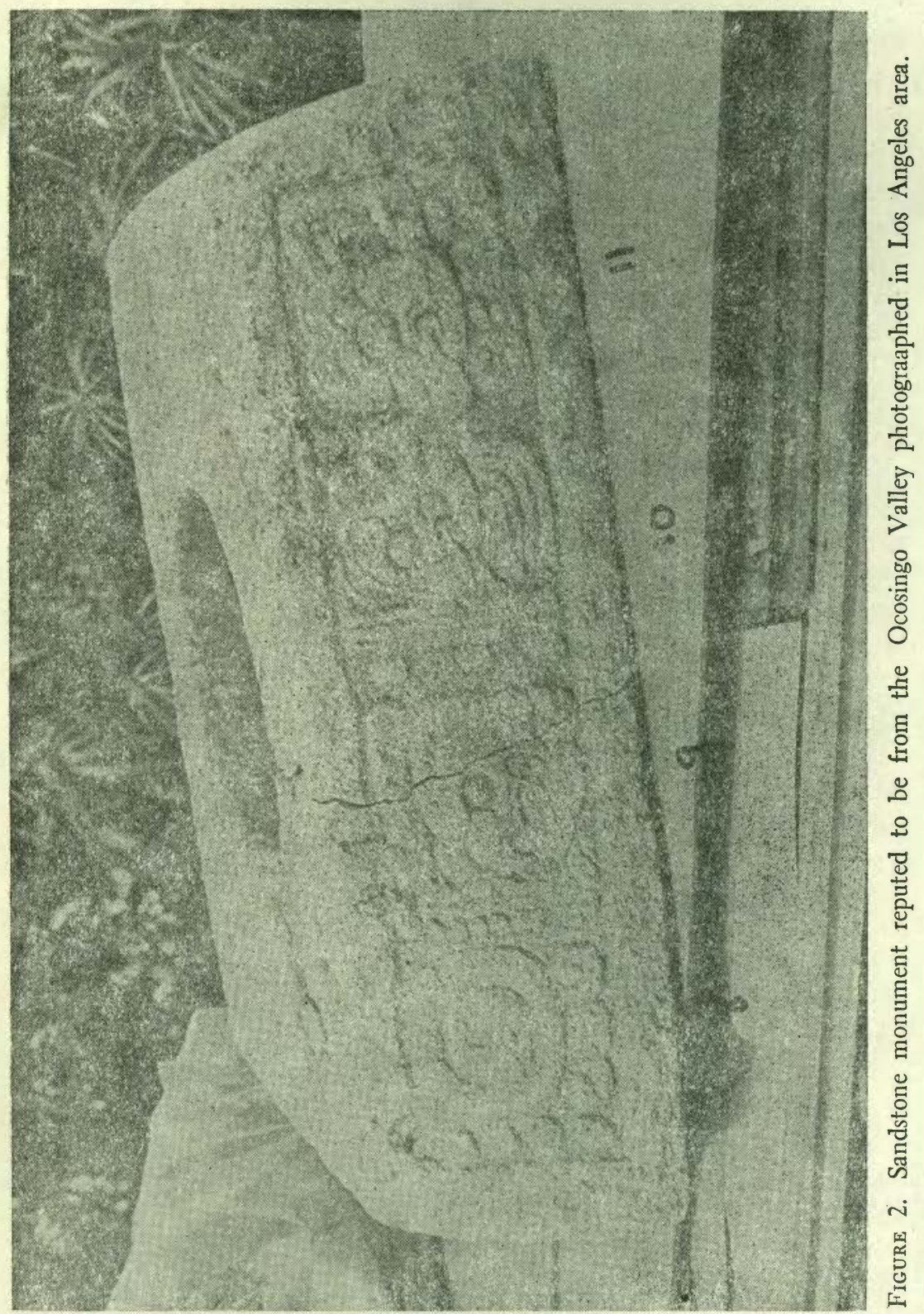

Estudios de Cultura Maya. Vol. XI, 1978

Instituto de Investigaciones Filológicas/

Centro de Estudios Mayas, UNAM

http://www.iifilologicas.unam.mx/estculmaya/ 

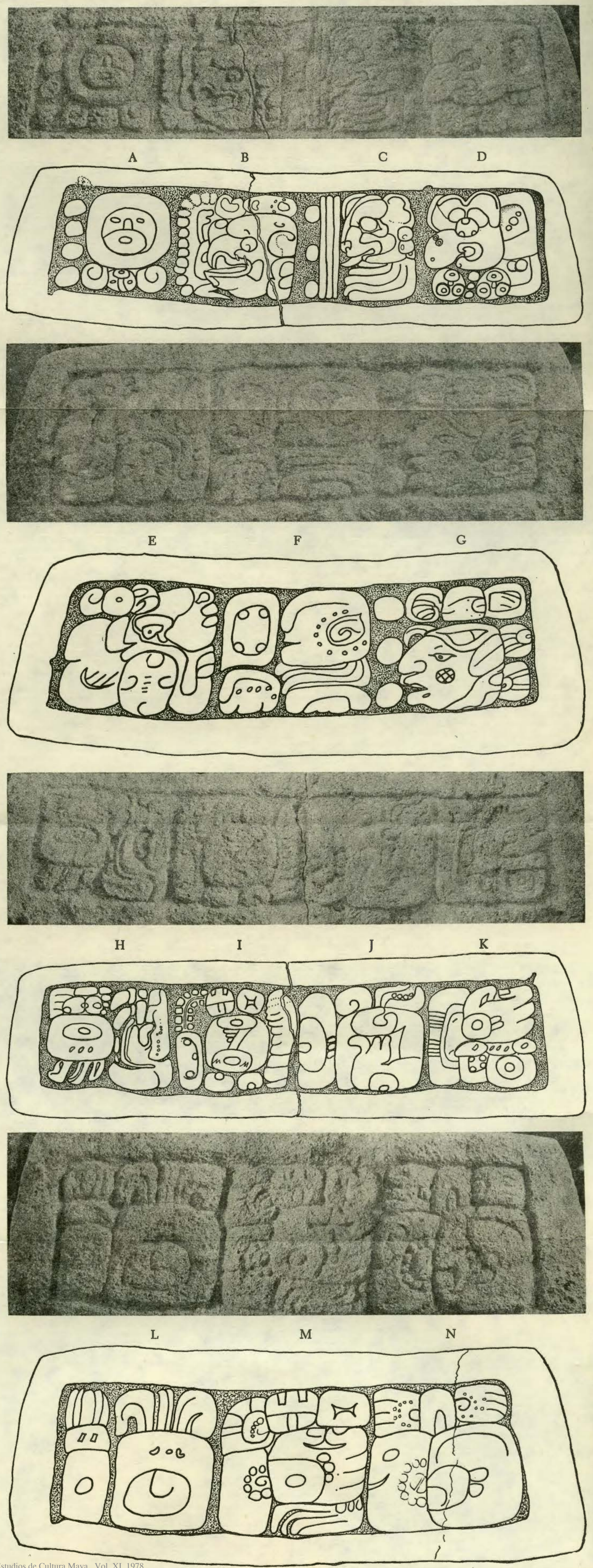

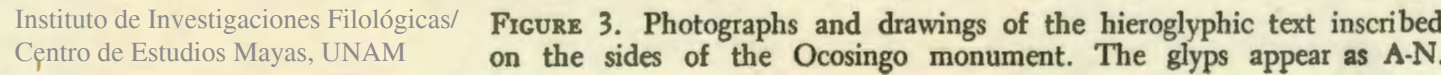


box can be identified as the Toniná emblem glyph. At the same time the form of the Ich mainsign is quite close to that of the emblem glyph on the Ocosingo monument dealt with here.

Two possible interpretations for the provenience of the emblem glyph and the monument result from this line of reasoning. First, it seems quite possible that a site of such size and importance as Toniná might have more than one variant form of emblem glyph. Case in point are Tikal and Palenque which display several emblem glyphs. Palenque in particular (Marcus 1976: 94) refers to itself in the texts with seven different forms of emblem glyph: T570, 590b, 1040, 793a, 1043, 1045, 1046. Toniná may thus have had two versions of its emblem glyph, one with the Ich mainsign and the other version on the monument in question.

Second, Baudez and Becquelin (1975: 12) have reported that there are 2 sites in the valley near Toniná which they identify as probable secondary centers to Toniná. The emblem glyph on the Ocosingo monument may identify one of these two secondary centers. A similar inscribed stone monument to the one discussed here (even including measurements) was found by Franz Blom (1957: figura 35), in Santotón, Chiapas some $10 \mathrm{~km}$ from Toniná. If the similar measurements of the Santotón stone and an emblem glyph (illustration not available) in the text of that monument could be matched with the emblem glyph discussed here on the Ocosingo monument, the identity of the emblem glyph and the monument might be resolved.

A second possible emblem glyph on the Ocosingo monument is carved at Ml. It lacks the customary water-group prefix but still may operate in an emblem glyph with its Manik mainsign and the customary T168 superfix. Heinrich Berlin (personal communication) rightly feels that this compound should not be seriously considered as an emblem glyph without the proper affixes and at least two other citations of the same compound elsewhere to confirm it as an emblem glyph.

The nature of the glyph compounds at $\mathrm{Jl}, \mathrm{Kl}, \mathrm{Ll}$, is uncertain but they may operate as nominal glyphs. It may be of significance that both the compound at $\mathrm{Kl}$ and the possible emblem glyph at M1 have Manik mainsigns. The function of the terminal compound, T28: 528.513 remains unclear. It might be a replacement of the Imix-comb-Imix compound which frequently terminates glyph clauses. The text of the stone box illustrated by Michael Coe (1973: 33) which carries the Toniná emblem glyph ends with a separate Muluc compound and Cauac compound which is reminiscent of the 
single terminal Muluc-Cauac compound terminating the Ocosingo text. Both of these terminal combinations seem to duplicate the Imix-comb-imix function.

\section{BIBLIOGRAPHY}

Baudez, C. F. and Pierre Becquelin

1975 Une cité Maya au Mexique:

Toniná, Archeologia,

80 Mars: 10-22.

Baudez, D. F. and Pierre Becquelin

1973 Recherches Archéologiques à Toniná, Chiapas, Mexique.

BerLin, Heinrich

Journal de la Société des Américanistes, LXI:255-257.

BLOM, FraNz

(Personal Communication)

1957 La Selva Lacandona. México.

Blom, Franz and O. LA FARGE

1926-1927 Tribes and Temples.

Middle American Research Series, Pub. 1.

Vols. 1 and 2. New Orleans.

Coe, Michael D.

The Maya Scribe and his World.

Marcus, Joyce

The Grolier Club.

1976 Emblem and State in the Classic Maya Lowlands:

An Epigraphic Approach to Territorial Organization.

Thompson, J.E.S.

Dumbarton Oaks, Washington, D.C.

1942 "Observations on Glyph G of the Lunar Series."

Notes on Middle American Archaeology and Ethnology, No. 7.

1962 A Catalog of Maya Hieroglyphs. Norman. 